\section{ENZYMATIC INACTIVATION OF GENTAMICIN G COMPONENTS BY CELL-FREE EXTRACT FROM PSEUDOMONAS AERUGINOSA}

\section{Sir :}

Gentamicin C, a broad spectrum antibiotic complex, has been isolated from submerged cultures of Micromonospora purpurea ${ }^{1}$. The available form of gentamicin is a mixture of three components called gentamicins $\mathrm{C}_{1}$, $\mathrm{C}_{2}$ and $\mathrm{C}_{12}{ }^{2}$. The structures of these components have been determined and were described by Cooper et al. ${ }^{3,4)}$, as shown in Fig. 1.

Fig. 1. Gross structures of the gentamicin $\mathrm{C}$ components

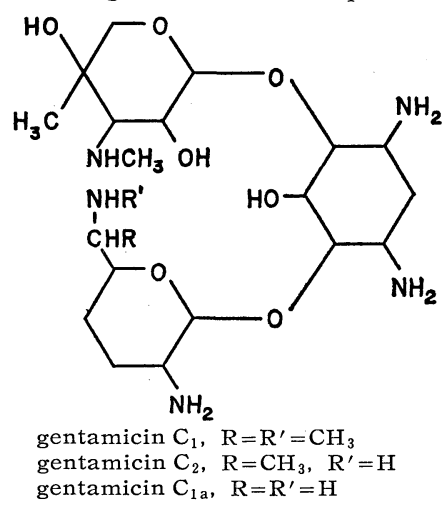

The lower sugar in the figure is a $2,3,4$, 6-tetradeoxyamino sugar, a novel compound which has been designated purpurosamine, and contains no hydroxyl groups in the rings. By contrast, several other 2-deoxystreptamine-containing aminoglycosidic antibiotics including kanamycin, neomycin and paromomycin contain a hydroxyl group at position 3 of the amino sugar. This difference is considered to be of biological significance, because several other aminoglycosidic antibiotics were found to be inactivated by the strains of bacteria resistant to the drugs. The inactivating enzymes were known to be capable of specifically phosphorylating ${ }^{5 \sim 10}$ ) antibiotics at the 3-hydroxy position of the amino sugar or acetylating kanamycin on the amino group of the amino sugar ${ }^{5,11}$. Similarly, we reported that a kanamycinphosphorylating enzyme from a resistant strain of Pseudomonas aeruginosa inactivated paromomycin, mannosylparomomycin, ami- nodeoxykanamycin and neomycin but did not inactivate lividomycin ${ }^{12}$ and gentamicin C components, which were devoid of a hydroxy group at position 3 of the amino sugar ${ }^{13)}$. TANAKA ${ }^{14)}$ also reported that gentamicin $\mathrm{C}$ components were not inactivated by gentamicin-resistant strains of $P$. aeruginosa; the resistance mechanism being a decrease to the sensitivity of ribosome to the drug.

Recent studies in this laboratory have disclosed that the enzyme from gentamicin-resistant $P$. aeruginosa inactivated the gentamicin $\mathrm{C}$ components in the presence of magnesium acetate, adenosinetriphosphate and coenzyme A. Crude cell-free extracts from the organism were prepared by the method described previously ${ }^{13)}$. The organism was harvested by centrifugation, washed

Table 1. Inactivation of gentamicin $\mathrm{C}$ components by $P$. aeruginosa

\begin{tabular}{|c|c|c|c|c|}
\hline \multirow{2}{*}{ Bacterial strain } & \multirow{2}{*}{$\begin{array}{c}\mathrm{MIC} * \\
(\mathrm{mcg} / \mathrm{ml})\end{array}$} & \multicolumn{3}{|c|}{$\begin{array}{c}\text { Percent } \\
\text { inactivation }\end{array}$} \\
\hline & & $\mathrm{C}_{1}$ & $\mathrm{C}_{2}$ & $\mathrm{C}_{1 \mathrm{a}}$ \\
\hline P. aeruginosa 99 & $>200$ & 99 & 97 & 98 \\
\hline P. aeruginosa cape 18 & 200 & 70 & 70 & 90 \\
\hline P. aeruginosa $\mathrm{TK}-157$ & 6,25 & 2 & 0 & 0 \\
\hline$P$. aeruginosa TI-13 & 3.13 & 4 & 0 & 0 \\
\hline
\end{tabular}

The reaction mixture contained $: 0.3 \mathrm{ml}$ of the $\mathrm{S}-105$ fraction $(10 \mathrm{mg}$ protein per $\mathrm{ml}), 0.1 \mathrm{ml}$ of $40 \mathrm{~mm}$ disodium adenosinetriphosphate (ATP), $0.1 \mathrm{ml}$ of $2.0 \mathrm{~mm}$ coenzyme $\mathrm{A}(\mathrm{CoA}), 0.1 \mathrm{ml}$ of $1.0 \mathrm{~mm}$ antibiotic and 0.4 $\mathrm{ml}$ of TMK solution. After 3 hours of incubation at $30^{\circ} \mathrm{C}$, the reaction was stopped by heating the mixture at $80^{\circ} \mathrm{C}$ for 5 minutes. The antibiotic activity in the reaction mixture was determined by the paper-disk method.

* MIC : minimum inhibitory concentration of gentamicin C.

Table 2. Requirement for the inactivation of gentamicin $\mathrm{C}$ by the cell-free extract of $P$. aeruginosa 99

\begin{tabular}{|c|c|c|c|}
\hline \multirow{2}{*}{ Reaction mixture } & \multicolumn{3}{|c|}{ Percent inactivation } \\
\hline & $\mathrm{C}_{1}$ & $\mathrm{C}_{2}$ & $\mathrm{C}_{1 \mathrm{a}}$ \\
\hline Complete system ${ }^{a}$ & 97.6 & 97.0 & 99.0 \\
\hline$-(\mathrm{S}-105)$ & 0 & 0 & 0 \\
\hline$-\mathrm{ATP}$ & 0 & 0 & 0 \\
\hline$-(\text { Acetate }, \mathrm{CoA})^{b}$ & 0 & 0 & 0 \\
\hline$(\mathrm{S}-105)$, acetyl CoA $A^{c}$ & 97.5 & 96.2 & 94.7 \\
\hline
\end{tabular}

The inactivating reacticn was carried out at $30^{\circ} \mathrm{C}$ for 1 hour and the remaining activity of the antibiotic was assayed.

$a$ : see the footnote of Table 1 .

$b$ : Magnesium chloride was used instead of magnesium acetate in TMK solution.

$c$ : ATP, CoA and acetate were replaced by $0.2 \mathrm{ml}$ of $5.0 \mathrm{~mm}$ acetyl CoA.

The same buffer as shown in $b$ was used. 
three times with $\mathrm{M} / 10 \mathrm{TMK}$ solution $(\mathrm{M} / 10$ tris buffer containing $0.06 \mathrm{M} \mathrm{KCl}, \quad 0.01 \mathrm{M}$ magnesium acetate and $0.006 \mathrm{M} 2$-mercaptoethanol, $\mathrm{pH}$ 7.8) and resuspended in the same buffer. The cell suspension was disrupted sonically at $20 \mathrm{Kc}$ for 10 minutes. After treatment with deoxyribonuclease $(4 \mathrm{mcg} / \mathrm{ml})$ at $37^{\circ} \mathrm{C}$ for 15 minutes, the sonicated suspension was centrifuged at $10,000 \times g$ for 20 minutes. The supernatant thus obtained was subjected to further centrifugation at $105,000 \times g$ for 60 minutes and the supernatant was dialyzed for 2 hours against cold TMK solution. The solution was designated the S-105 fraction. As shown in Table 1, gentamicin $\mathrm{C}$ components were inactivated by the $\mathrm{S}-105$ fraction prepared from gentamicin-resistant strains but not by fractions from gentamicin-sensitive strains.

Next we examined the requirements for the inactivation of gentamicin $\mathrm{C}$ components. As can be seen in Table 2, the inactivating activity was lost without ATP or without both coenzyme $\mathrm{A}$ and acetate, but restored completely by addition of the three agents, i.e., ATP, coenzyme A and acetate. But these three agents could be replaced by acetyl coenzyme A. From these results, it is concluded that gentamicin $\mathrm{C}$ components are inactivated by acetylation. The inactivation mechanism and the inactivated position of each of the gentamicin $\mathrm{C}$ components is still being elucidated and will be described elsewhere.

\section{Acknowledgement}

We wish to thank H. UMEZAWA, Institute of Microbial Chemistry, Tokyo, M. J. Weinstein and R. VARIN, the Schering Co., U. S. A. for their helpful advices in carrying out these experiments.

\section{Susumu Mitsuhashi \\ Fujio Kobayashi *}

Masahito Yamaguchi

Department of Microbiology, School of Medicine, Gunma University, Maebashi, Japan

* Present address: Tokyo Research Laboratories, Kowa Co., Tokyo, Japan

(Received April 1, 1971)

\section{References}

1) Weinstein, M. J.; G. M. Luedemann, E. M. ODEN \& G. H. WAGMAN : Gentamicin, a new broad spectrum antibiotic complex. Antimicr. Agents \& Chemoth. $-1963: 1 \sim 13,1964$

2) Wagman, G. H. ; J. A. Marquez \& M. J. Weinstein: Chromatographic separation of the components of the gentamicin complex. J. Chromatogr. $34: 210 \sim 215,1968$

3) Cooper, D. J. \& M. D. Yudis: The gentamicin antibiotics. Isolation and characterization of methyl garosaminide, a novel amino hexopyranoside. Chem. Commun. (London) $16: 821 \sim 822,1967$

4) Cooper, D. J. \& H. M. Marigliano : Recent developments in the chemistry of gentamicin. J. Infect. Dis. $119: 342 \sim 344,1970$

5) Окамото, S. \& Y. SuzukI : Chloramphenicol-, dihydrostreptomycin- and kanamycin-inactivating enzyme from multiple-drug-resistant Escherichia coli carying episome 'R'. Nature 208: 1301 1303, 1965

6) Umezawa, H.; M. Okanishi, S. Kondo, K. Hamana, R. Utahara, K. Maeda \& S. MitsuHASHI : Phosphorylative inactivation of aminoglycosidic antibiotics by Escherichia coli carrying $\mathrm{R}$ factor. Science $157: 1559 \sim 1561$, 1967

7) Umezawa, H.; O. Doi, M. Ogura, S. Kondo $\&$ N. TANAKA: Phosphorylation and inactivation of kanamycin by Pseudomonas aeruginosa. J. Antibiotics 21: 154 155, 1968

8) Doi, O.; M. Ogura, N. Tanaka \& H. UmeZAWA : Inactivation of kanamycin, neomycin and streptomycin by enzymes obtained in cells of Pseudomonas aeruginosa. Appl. Microbiol. $16: 1276 \sim 1281,1968$

9) Dor, O.; S. Kondo, N. Tanaka \& H. UmezAWA : Phosphorylating enzyme from Pseudomonas aeruginosa. J. Antibiotics $22: 273$ $\sim 282,1969$

10) Dor, O.; M. Miуamoto, N. Tanaka \& H. UMEZAWA : Inactivation and phosphorylation of kanamycin by drug-resistant Staphylococcus aureus. Appl. Microbiol. 16 : 1282 1284, 1968

11) Umezawa, H.; M. Okanishi, R. Utahara, K. MAEDA \& S. Kondo : Isolation and structure of kanamycin inactivated by a cell-free system of kanamycin-resistant $E$. coli. J. Antibiotics $20: 136 \sim 141,1967$

12) Oda, T.; T. Mori, Y. Kyotani \& M. NaKayama : Studies on new antibiotic lividomycins. IV. Structure of lividomycin A. J. Antibiotics. In press

13) Kobayashi, F.; M. Yamaguchi \& S. MitsuHASHI : Phosphorylated inactivation of aminoglycosidic antibiotics by Pseudomonas aeruginosa. Japan. J. Microbiol. $15: 265 \sim$ 272,1971

14) Tanaka, N. : Biochemical studies on gentamicin resistance. J. Antibiotics 23:469 471,1970 